\title{
Água no solo e rendimento do trigo, soja e milho associados ao El Niño Oscilação Sul
}

\author{
Cleber Maus Alberto(1), Nereu Augusto Streck(1), Arno Bernardo Heldwein ${ }^{(1)}$, Galileo Adeli Buriol(1) \\ e Sandro Luis Petter Medeiros ${ }^{(1)}$
}

(1)Universidade Federal de Santa Maria, Centro de Ciências Rurais, Dep. de Fitotecnia, CEP 97105-900 Santa Maria, RS.
E-mail: cleberalb@yahoo.com.br, nstreck1@smail.ufsm.br, heldwein@ccr.ufsm.br, galileo@unifra.br, sandro@ccr.ufsm.br

Resumo - O objetivo deste trabalho foi simular o conteúdo de água disponível no solo e o rendimento das culturas de trigo, soja e milho, em Santa Maria, RS, e associá-los ao fenômeno El Niño Oscilação Sul (ENOS). O período estudado foi de 1969 a 2003. Aágua disponível no solo e o rendimento das culturas foram calculados com modelos matemáticos disponíveis na literatura. A água disponível no solo foi representada pela fração de água transpirável no solo pelas plantas. Foi constatado que a menor disponibilidade hídrica no solo está associada a anos neutros, e a maior disponibilidade hídrica está relacionada a eventos do El Niño. Os anos de La Niña foram os mais favoráveis ao rendimento de grãos da cultura de trigo, enquanto os anos de El Niño foram os mais favoráveis ao rendimento de grãos de soja e milho. Ficou evidente que os anos classificados como neutros, em relação ao ENOS, são os de maior risco de perda de rendimento de grãos destas duas culturas de verão, em conseqüência da menor disponibilidade hídrica no solo, o que é uma informação importante no planejamento de estratégias para o agronegócio relativamente a uma previsão do fenômeno ENOS.

Termos para indexação: Triticum aestivum, Glycine max, Zea mays, La Niña, balanço hídrico do solo.

\section{Soil water and wheat, soybean, and maize yields associated to EI Niño Southern Oscilation}

\begin{abstract}
The objective of this study was to simulate soil water content, and wheat, soybean and maize yields, in Santa Maria, RS, Brazil, and link their interannual variability to El Niño Southern Oscillation (ENSO). The period studied was 1969 to 2003. Soil water content and the yields of wheat, soybean and maize were simulated with models available in the literature. Soil water content was represented by the fraction of transpirable soil water. The results showed that the lowest soil water content in Santa Maria is associated to neutral years and the highest soil water is associated to El Niño events. La Niña years were more favorable to high wheat yield, whereas El Niño years were more favorable to high soybean and maize yields. It was evident that years classified as neutral years in respect to ENSO are riskier to grain yields of soybean and maize crops, which is an important information for planning strategies in agribusiness considering ENSO forecast.
\end{abstract}

Index terms: Triticum aestivum, Glycine max, Zea mays, La Niña, soil water budget.

\section{Introdução}

El Niño Oscilação Sul (ENOS) é um fenômeno de grande escala, que ocorre na região do Oceano Pacífico Equatorial e afeta o tempo e o clima em diversos locais do Globo Terrestre (Cane, 2001), inclusive nas Regiões Nordeste e Sul do Brasil (Berlato \& Fontana, 2003). As fases quente (El Niño) e fria (La Niña) do ENOS são fenômenos cíclicos, de duração e ocorrência variável ou aperiódica (Glantz, 2001). Geralmente, o fenômeno ENOS começa no início do segundo semestre de um ano e termina no final do primeiro semestre do ano seguinte (Berlato \& Fontana, 2003; Berlato et al., 2005).

Na Região Sul do Brasil, um dos principais impactos da fase quente e fria do ENOS é sobre a freqüência, a intensidade e a quantidade de precipitação pluvial (Fontana \& Berlato, 1997; Berlato \& Fontana, 2003). Como conseqüência, a variabilidade interanual da produção agrícola, no Estado do Rio Grande do Sul, está associada ao ENOS (Berlato \& Fontana, 1999; Berlato et al., 2005), pois a precipitação pluvial é a principal fonte de água para os agroecossistemas gaúchos. 
Segundo Berlato \& Fontana (2003), em anos de El Niño, as deficiências hídricas são menores em todo Estado do Rio Grande do Sul, enquanto em anos de La Niña, a tendência é de que as deficiências hídricas sejam maiores do que em anos neutros, na metade Sul do Estado. No entanto, a tendência de maiores deficiências hídricas, em anos de La Niña, não se confirmou em todas as regiões ecoclimáticas do Rio Grande do Sul, como, por exemplo, o Baixo Vale do Uruguai e Missões, onde a deficiência hídrica foi maior nos anos neutros do que nos anos de La Niña (Berlato \& Fontana, 2003). O estudo de Berlato \& Fontana (2003) não incluiu a região ecoclimática da depressão central do Rio Grande do Sul, onde Santa Maria está situada, que é uma transição entre a metade Norte e Sul do Estado, e uma região que tem na produção agrícola uma das principais atividades econômicas. Assim, é importante que um trabalho desta natureza seja estendido para essa região, o que constituiu o incentivo para a realização deste trabalho.

O trigo é a principal cultura de inverno, enquanto a soja e o milho são as principais culturas de verão do Estado do Rio Grande do Sul (Berlato \& Fontana, 2003).

Para estudos da associação da variabilidade interanual do rendimento das culturas com fenômenos meteorológicos, são úteis os dados de séries históricas, nem sempre disponíveis, como é o caso de Santa Maria. Neste caso, há a opção de se utilizarem dados de rendimento extraídos de estatísticas de órgãos governamentais, como a Companhia Nacional de Abastecimento (Conab) e o Instituto Brasileiro de Geografia e Estatística (IBGE) (Berlato \& Fontana, 1999; Cunha et al., 1999; Berlato et al., 2005). No entanto, esses dados devem ser corrigidos, retirando-se a tendência tecnológica, para que sejam levadas em conta as mudanças, principalmente no manejo de genótipos ao longo dos anos, o que pode ser uma desvantagem já que esta correção é realizada por métodos estatísticos empíricos. Outro inconveniente de se utilizar este tipo de dados é o de que se tratam de informações regionais que, portanto, não representam as condições ambientais (solo e clima) de agroecossistemas locais.

Uma opção para superar as desvantagens do uso de estatísticas governamentais, em estudos que envolvem séries históricas longas, é a utilização de modelos de simulação do rendimento das culturas em resposta a fatores ambientais (Andresen et al., 2001). Entre os diferentes modelos de simulação, encontram-se os matemáticos mecanísticos simplificados, que utilizam um reduzido número de informações de entrada, são compostos por funções matemáticas robustas, e são intermediários entre modelos de regressão e modelos complexos. Exemplos desses tipos de modelos mecanísticos simplificados são aqueles propostos por Sinclair (1986), Amir \& Sinclair (1991a, 1991b) e Muchow \& Sinclair (1991).

O objetivo deste trabalho foi simular o conteúdo de água disponível no solo e o rendimento das culturas de trigo, soja e milho, em Santa Maria, RS, e associá-lo ao fenômeno ENOS.

\section{Material e Métodos}

Utilizaram-se dados diários, do período de julho de 1969 a dezembro de 2003, de temperatura máxima e mínima do ar, brilho solar e precipitação pluvial, coletados na estação climatológica principal do Instituto Nacional de Meteorologia, localizada no campo experimental do Departamento de Fitotecnia, da Universidade Federal

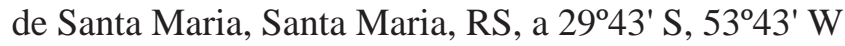
e altitude de $95 \mathrm{~m}$.

A densidade de fluxo de radiação solar global incidente, necessária nos modelos matemáticos de simulação do rendimento e da água disponível no solo, foi estimada pela equação de Ängstrom, a partir do brilho solar, com coeficientes mensais para Santa Maria.

Os coeficientes de solo (capacidade de campo e ponto de murcha permanente) utilizados para a simulação, são referentes ao Argissolo Vermelho-Amarelo distrófico arênico (Embrapa, 1999), pertencente à unidade de mapeamento São Pedro, representativo da região. O conteúdo de água disponível no solo foi representado pela fração porcentual de água transpirável no solo para as plantas (FTSW):

FTSW $=100[(C A-P M P) /(C C-P M P)]$

em que CA é o conteúdo atual de água no solo $\left(\mathrm{cm}^{3} \mathrm{~cm}^{-3}\right)$, PMP é o conteúdo de água no solo no ponto de murcha permanente $\left(\mathrm{cm}^{3} \mathrm{~cm}^{-3}\right)$, e CC é o conteúdo de água no solo na capacidade de campo $\left(\mathrm{cm}^{3} \mathrm{~cm}^{-3}\right)$. Os valores de PMP e CC são apresentados na Tabela 1.

O rendimento de grãos das culturas do trigo, soja e milho foi simulado para a condição potencial e com restrição hídrica no solo. A condição potencial refere-se ao rendimento de grãos simulado sem restrição hídrica no solo, durante todo o ciclo de desenvolvimento da cultura. O rendimento de grãos do trigo, na condição potencial e com restrição hídrica no solo, foi simulado com os modelos de Amir \& Sinclair (1991a, 1991b), respectivamente. $\mathrm{O}$ número final de folhas na haste 
principal e o acúmulo térmico entre o aparecimento de duas folhas sucessivas (filocrono) (Amir \& Sinclair, 1991a, 1991b) foram de 11 folhas e 113 graus-dia (GD), respectivamente, para a cultivar BRS 179 , genótipo de trigo recomendado para a Região Sul do Brasil (Embrapa, 2004a).

Nos modelos deAmir \& Sinclair (1991a, 1991b), o ciclo de desenvolvimento da cultura do trigo é dividido em quatro fases: da emergência ao crescimento da haste principal; do crescimento da haste principal à antese; da antese ao início do enchimento de grãos; e do início do enchimento de grãos à maturação fisiológica. A duração destas fases é de, respectivamente, 1.243, 90, 212 e 585 GD acima de $0^{\circ} \mathrm{C}$. Para o cálculo da biomassa e rendimento de grãos, utilizou-se uma eficiência do uso de radiação solar (EUR) de $0,9 \mathrm{~g} \mathrm{MJ}^{-1}$ (Moreira et al., 1999).

O rendimento de grãos da soja, na condição potencial e com restrição hídrica no solo, foi calculado por meio do modelo de Sinclair (1986). Para a condição potencial, eliminaram-se os algoritmos de resposta ao deficit hídrico do modelo de Sinclair (1986). As datas de término de crescimento foliar e início do enchimento de grão foram simuladas para a cultivar Bragg, com o modelo nãolinear de resposta do desenvolvimento à temperatura e ao fotoperíodo propostos por Sinclair et al. (1991), utilizando-se dados de um ensaio realizado no campo experimental do Departamento de Fitotecnia da UFSM, Santa Maria, RS, no ano 1983/1984, sendo que o término do crescimento foliar corresponde ao dia de estádio de desenvolvimento 1 e o início do enchimento de grãos ao dia de estádio 1,8 do modelo de Sinclair et al. (1991).

O rendimento de grãos de milho, na condição potencial e com restrição hídrica no solo, foi calculado utilizandose os modelos de Muchow et al. (1990) e Muchow \& Sinclair (1991), respectivamente, com os coeficientes dos modelos originais.

Os modelos de Amir \& Sinclair (1991b), Sinclair (1986) e Muchow \& Sinclair (1991) simulam o balanço hídrico no solo para as culturas de trigo, soja e milho, respectivamente.

Tabela 1. Capacidade de armazenamento de água, de cada horizonte do solo da unidade São Pedro, na capacidade de campo (CC) e ponto de murcha permanente (PMP), usados no estudo.

\begin{tabular}{cccc}
\hline Horizonte & $\begin{array}{c}\text { Profundidade } \\
(\mathrm{cm})\end{array}$ & $\begin{array}{c}\mathrm{CC} \\
\left(\mathrm{cm}^{3} \mathrm{~cm}^{-3}\right)\end{array}$ & $\begin{array}{c}\text { PMP } \\
\left(\mathrm{cm}^{3} \mathrm{~cm}^{-3}\right)\end{array}$ \\
\hline $\mathrm{A}_{\mathrm{P}}$ & $0-30$ & 0,232 & 0,116 \\
$\mathrm{~A}_{3}$ & $30-56$ & 0,234 & 0,140 \\
$\mathrm{~B}_{21}$ & $56-85$ & 0,234 & 0,175 \\
$\mathrm{~B}_{22}$ & $85-126$ & 0,306 & 0,218 \\
\hline
\end{tabular}

Na simulação do balanço hídrico do solo, além destes modelos, utilizou-se também o de Campbell \& Diaz (1988), em que o solo é dividido em seis camadas; a profundidade da primeira é de $0,15 \mathrm{~m}$ e a profundidade das demais camadas é definida de acordo com a profundidade máxima do sistema radicular de cada cultura.

As datas de semeadura das culturas adotadas na simulação foram 14 de junho para a cultura do trigo (Embrapa, 2004a), 15 de novembro para a cultura da soja (Embrapa, 2004b) e 15 de novembro para a cultura do milho (Maluf et al., 2000; Bergamaschi et al., 2004). A simulação foi iniciada em 1ㅇ/7/1969 com o solo na CC e finalizada em 31/12/2003.

As datas de maturação fisiológica, necessárias no modelo de Campbell \& Diaz (1988), foram obtidas pelos modelos de crescimento e desenvolvimento de Amir \& Sinclair (1991b) para o trigo, Sinclair (1986) para a soja e Muchow \& Sinclair (1991) para o milho. Todos os modelos utilizados funcionam numa escala diária.

O dia da colheita de cada cultura foi considerado o dia seguinte ao que completou acúmulo térmico de $233 \mathrm{GD}\left(\mathrm{T}_{\mathrm{b}}=5^{\circ} \mathrm{C}\right)$, após a completa maturação fisiológica. Quando houve precipitação pluvial acima de $5 \mathrm{~mm}$, no dia em que os 233 GD foram completados, aguardaram-se dois dias após o último dia de chuva, para o dia da colheita.

Considerou-se que, durante o período de pousio, não existia vegetação em crescimento ativo sobre a superfície do solo, e os restos culturais permaneceram sobre a superfície após a colheita. O cálculo da decomposição dos restos culturais após a colheita foi baseado nas equações propostas por Ghidey et al. (1985). A presença de resíduos sobre a superfície atenua a perda de água do solo por evaporação; esta atenuação foi calculada pela equação proposta por Gill \& Jalota (1996).

Os rendimentos de trigo, soja e milho (média de rendimento de todo o Estado do Rio Grande do Sul), durante o período de 1990 a 2003, obtidos da página eletrônica da Conab (2005), foram utilizados para testar os modelos de simulação do rendimento de grãos das três culturas. Não foi feita nenhuma correção tecnológica dos dados de rendimento, pois considerou-se que as mudanças tecnológicas, nesse período, afetaram menos a variabilidade anual do rendimento dessas culturas do que o efeito da variabilidade climática, o que é suficiente para testar se os modelos matemáticos são apropriados para este estudo.

Foram calculados os desvios ou resíduos absolutos de rendimento de grãos $\left(\mathrm{g} \mathrm{m}^{-2}\right)$ simulado e observado, como 
sendo a diferença entre rendimento da safra e a média de rendimento do período (1990-2003). Para testar se os modelos de simulação do rendimento das culturas são apropriados para este estudo, dois testes estatísticos foram usados: a comparação entre a média dos rendimentos simulados e observados, pelo teste $t$ Pareado (a 5\% de probabilidade de erro) (Andresen et al., 2001), e a comparação entre média de desvios simulados e observados, pelo teste não paramétrico de Spearman R.

Os dados sobre anos de ocorrência e intensidade dos eventos El Niño e La Niña, usados neste estudo, foram retirados da página eletrônica do Centro de Previsão do Tempo e Estudos Climáticos (Cptec, 2004). Como o fenômeno ENOS, geralmente, se inicia no segundo semestre de um ano e acaba no primeiro semestre do ano seguinte, os anos indicados se referem ao ano de início do fenômeno (El Niño: 1969, 1972, 1976, 1977, 1979, 1982, 1986, 1987, 1990, 1991, 1992, 1994, 1997, 2002; La Niña: 1970, 1973, 1974, 1975, 1983, 1984, 1988, 1995, 1998, 1999, 2000; Neutros: 1971, 1978, 1980, 1981, 1985, 1989, 1993, 1996, 2001, 2003).

Para relacionar a FTSW e o rendimento anual de grãos estimados para as culturas, com o fenômeno ENOS, os valores diários médios da FTSW, durante o ciclo de desenvolvimento (semeadura-colheita), e o rendimento anual de grãos estimado foram agrupados em anos de El Niño (EN), La Niña (LN) e Neutros (N), considerando-se o dia $1^{\circ}$ de julho do ano como início do evento, e o dia 30 de junho do ano seguinte, como o final. Com os dados de FTSW e rendimentos, foram calculados a média, a mediana e os percentis de 10, 25, 75 e 90 em anos EN, LN e N (Berlato \& Fontana, 2003; Berlato et al., 2005).

\section{Resultados e Discussão}

A diferença entre as médias do rendimento de grãos simulado e observado não diferiu significativamente pelo teste t Pareado, para as culturas do trigo, soja e milho. De acordo com Andresen et al. (2001), isto significa que os modelos de simulação de rendimento de grãos das culturas simulam, satisfatoriamente, a tendência dos rendimentos anuais e, portanto, podem ser utilizados com finalidade preditiva no presente estudo.

De modo geral, a amplitude dos desvios de rendimento simulado é maior do que a amplitude dos desvios de rendimento observado (Figura 1). Isto é esperado, pois os dados observados representam o rendimento médio de grãos de uma região (Estado do Rio Grande do Sul), enquanto que os dados simulados pelos modelos matemáticos referem-se a um local (Andresen et al., 2001). Nota-se também, na Figura 1, que não há tendência de aumento de rendimento das culturas, em razão da mudança tecnológica no período 1990-2003, o que confirma a não-necessidade de correção dos dados adotada neste estudo.

A correlação entre desvios de rendimento observado e simulado pelo teste de Spearman R, para as culturas
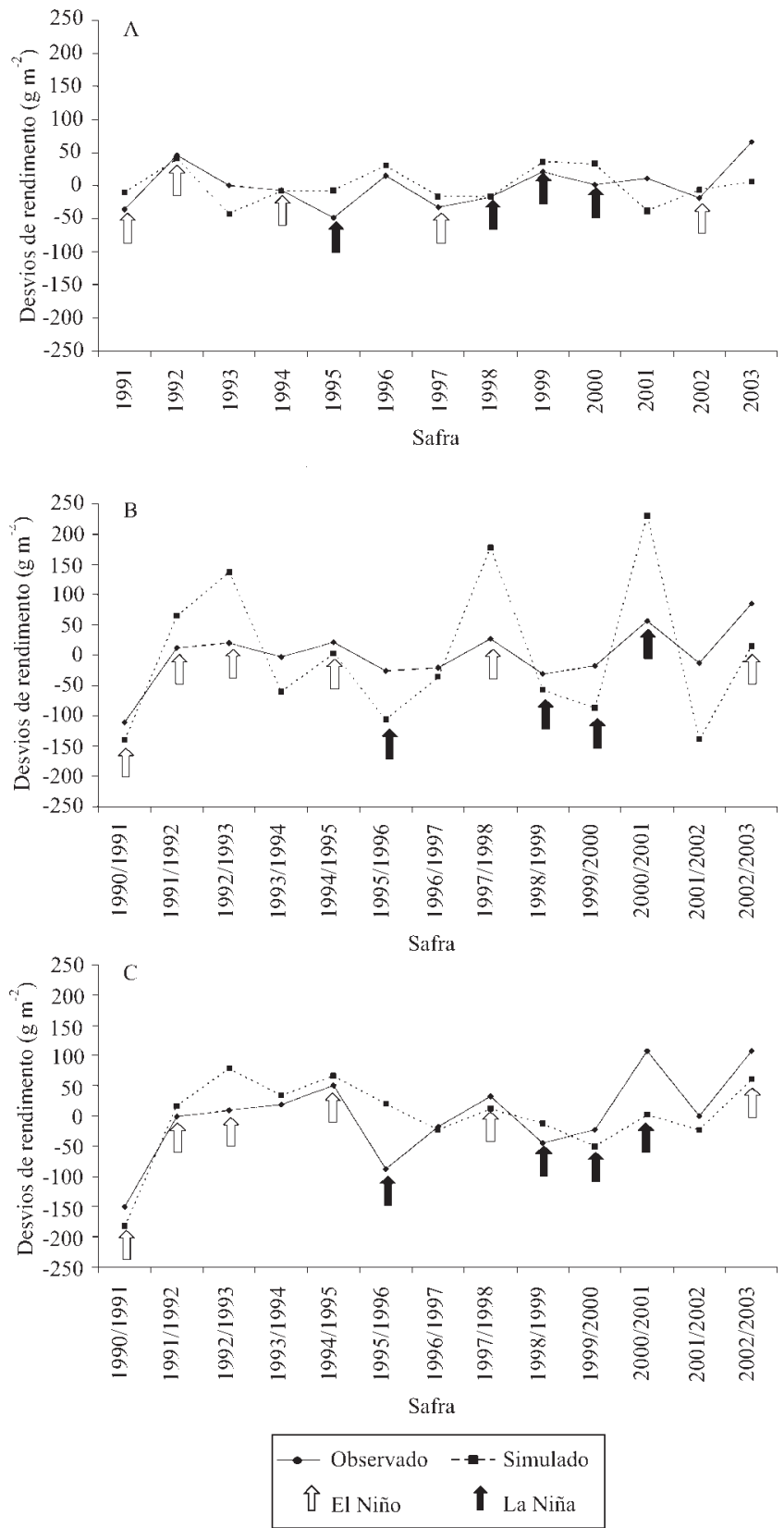

Figura 1. Desvios observados e simulados de rendimento de grãos de trigo (A), soja (B) e milho (C). Santa Maria, RS, 1990-2003. 
do trigo, soja e milho, foi de $0,51(\mathrm{p}=0,074), 0,79$ $(p=0,001)$ e $0,56(p=0,044)$, respectivamente, valores que foram considerados suficientes para rejeitar a hipótese $\mathrm{H}_{0}$ (correlação não-significativa), o que indica, novamente, que os modelos de simulação de rendimento de grãos das três culturas são apropriados para o presente estudo, pois os desvios de rendimento simulados seguem a mesma ordem de ranqueamento dos desvios de rendimento observados.

As diferenças entre rendimento simulado potencial e com restrição hídrica, no período 1969-2003, em Santa Maria, foram maiores para as culturas de verão (soja e milho, Figura 2 B e C) do que para a cultura do trigo (Figura 2 A). Em condições de restrição hídrica, o maior rendimento de trigo, simulado pelo modelo de Amir \& Sinclair (1991b), ocorreu na safra 1989 (371 $\left.\mathrm{g} \mathrm{m}^{-2}\right)$, e o menor rendimento na safra $1993\left(231 \mathrm{~g} \mathrm{~m}^{-2}\right)$, ambos anos $\mathrm{N}$ em relação ao fenômeno ENOS (Figura $2 \mathrm{~A}$ ).

O maior rendimento de soja com restrição hídrica, simulado pelo modelo de Sinclair (1986), foi na safra 2000/2001 (486 $\mathrm{g} \mathrm{m}^{-2}$ ), e o menor na safra 1985/1986 $\left(11 \mathrm{~g} \mathrm{~m}^{-2}\right)$, anos de $\mathrm{LN}$ e $\mathrm{N}$, respectivamente (Figura 2 B). Para a cultura do milho, o maior rendimento simulado com restrição hídrica ocorreu na safra 1971/1972 (601 $\mathrm{g} \mathrm{m}^{-2}$ ), e o menor rendimento na safra 1985/1986 (178 $\mathrm{g} \mathrm{m}^{-2}$ ), ambos anos N (Figura $2 \mathrm{C}$ ).

O modelo de Campbell \& Diaz (1988) simulou, na maioria das vezes, valores de FTSW superiores aos simulados pelos modelos de Amir \& Sinclair (1991b), Muchow \& Sinclair (1991) e Sinclair (1986) (Figura 3). Isto se deve às diferenças de estrutura e concepção dos modelos utilizados. O maior e menor valor de FTSW, simulada pelo modelo de Amir \& Sinclair (1991) para a cultura do trigo, ocorreu nas safras 2002 (91\%) e 1970 (60\%), anos de EN e LN, respectivamente. Pelo modelo de Campbell \& Diaz (1988), o maior e menor valor de FTSW para a cultura do trigo foi simulado nas safras 2002 (99\%) e 1978 (61\%), anos de EN e N, respectivamente. Para a cultura da soja, o maior valor de FTSW simulado pelo modelo de Sinclair (1986) foi da safra 1997/1998 (64\%), e o menor foi da safra 1985/1986 (17\%), anos considerados de EN e N, respectivamente. Pelo modelo de Campbell \& Diaz (1988), o maior e o menor FTSW foram nos mesmos anos, apenas com valores diferentes, ou seja, 1997/1998 (91\%) e 1985/1986 (10\%). Para a cultura do milho, pelo modelo de Muchow \& Sinclair (1991), o maior e o menor valor de FTSW foram simulados em anos N, 2000/2001 (81\%) e 1985/1986 (21\%), e pelo modelo de Campbell
\& Diaz (1988) o maior FTSW ocorreu em 1997/1998 (89\%), ano de EN, e o menor FTSW ocorreu em 1978/1979 (43\%), ano considerado $\mathrm{N}$.

Para a cultura do trigo (Figura 3 A e B), pelo modelo de Amir \& Sinclair (1991b), a proporção de anos com FTSW abaixo da média dos anos N foi de 23\% (3/13) em anos de EN, 36\% (4/11) em anos de LN, e 50\% (5/10) em anos N; e pelo modelo de Campbell \& Diaz (1988),
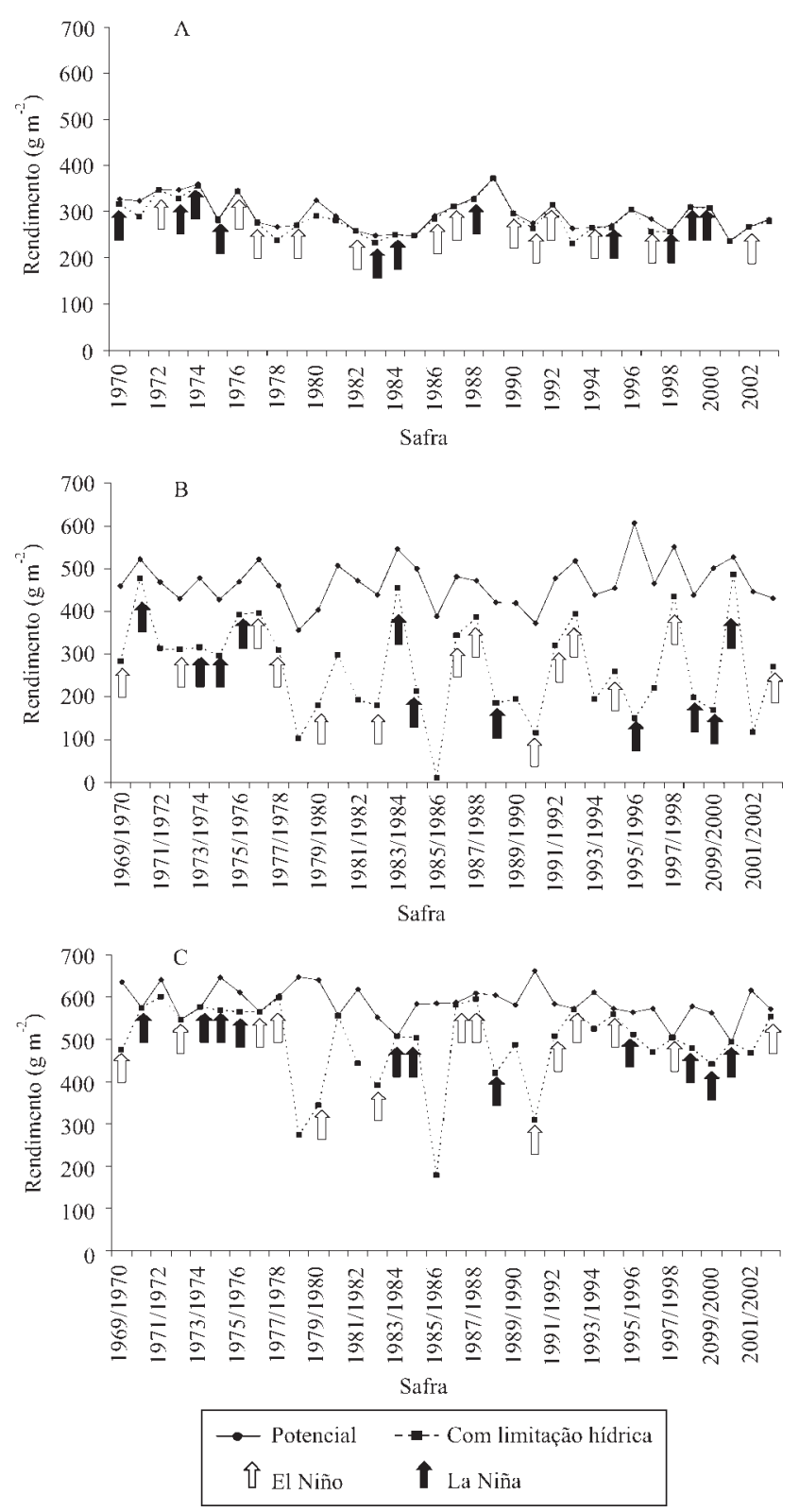

Figura 2. Variabilidade interanual do rendimento de grãos de trigo (A), soja (B) e milho (C), simulado para as condições potencial e com limitação hídrica no solo. Santa Maria, RS, 1969-2003. 
$15 \%(2 / 13)$ em anos de EN, 18\% (2/11) em anos de LN e $20 \%(2 / 10)$ em anos $\mathrm{N}$.

Para a cultura da soja (Figura 3 C e D), pelo modelo de Sinclair (1986), a FTSW ficou abaixo da média dos anos N
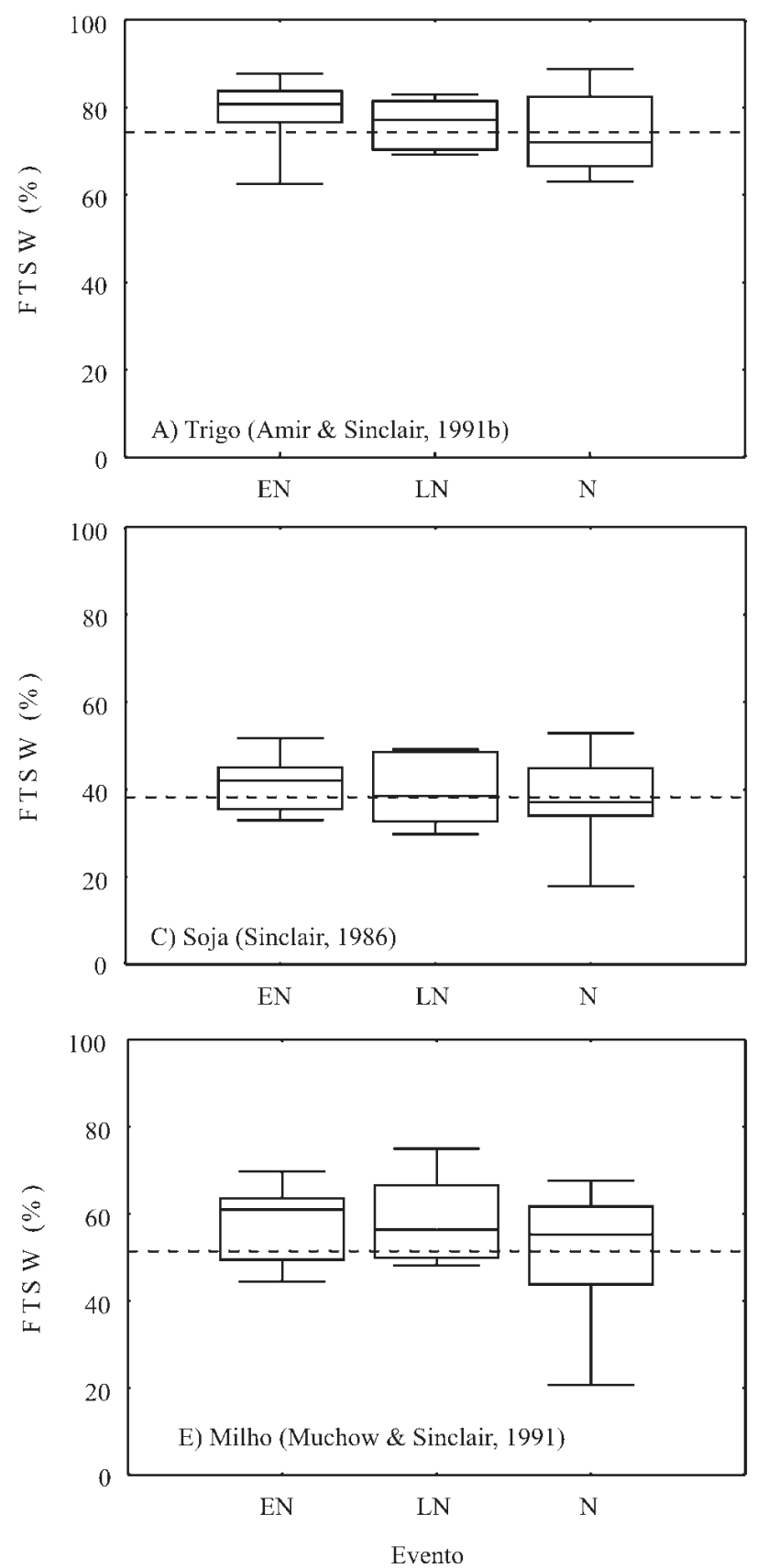

em 36\% (5/14) dos anos de EN, em 45\% (5/11) dos anos de $\mathrm{LN}$, e em 56\% (5/9) dos anos N; e pelo modelo de Campbell \& Diaz (1988), em 21\% (3/14) dos anos de EN, em 18\% (2/11) dos anos de LN e em 44\% (4/9) dos anos N.
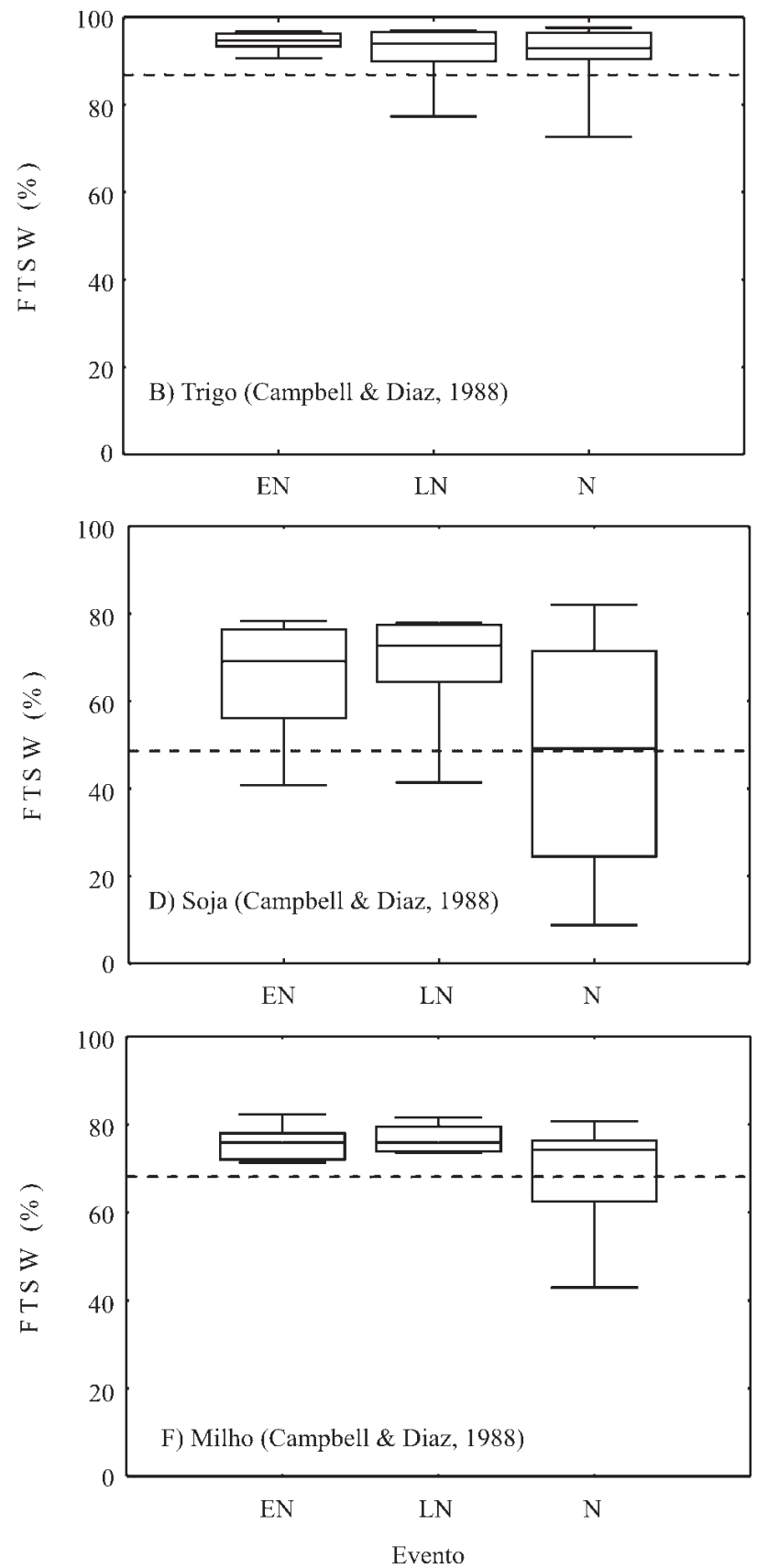

Figura 3. Distribuição da fração porcentual de água transpirável no solo (FTSW), no período de 1969-2003, associado aos eventos de El Niño (EN), La Niña (LN) e Neutros (N), para as culturas do trigo (A, B), soja (C, D) e milho (E, F), para Santa Maria, RS, simulada com diferentes modelos matemáticos. A linha cheia horizontal, no interior da caixa, representa o percentil de 50 (mediana); a linha tracejada representa a média dos anos neutros; o final das caixas representa os percentis de 25 e 75; as barras representam os percentis de 10 e 90. Os valores de FTSW correspondem à média do período, entre a semeadura e maturação fisiológica das culturas. 
Para a cultura do milho (Figura 3 E e F), pelo modelo de Muchow \& Sinclair (1991), a FTSW ficou abaixo da média dos anos N em 29\% (4/14), em 27\% (3/11) e em $44 \%$ (4/9) dos anos de EN, LN e N, respectivamente; e pelo modelo de Campbell \& Diaz (1988), em nenhum dos anos de EN, em 9\% (1/11) dos anos de LN e em 33\%(3/9) dos anos N. Em resumo, independentemente do modelo de simulação da FTSW e da cultura, os anos neutros são os que apresentam maior freqüência de menor disponibilidade de água para as culturas.

A variabilidade interanual do rendimento das culturas foi maior na simulação com restrição hídrica do que simulação na condição potencial (Figura 2). A simulação com restrição hídrica é mais realista e representativa dos sistemas de cultivos não irrigados, utilizados no Rio Grande do Sul, do que a condição potencial. Portanto, o efeito do ENOS sobre o rendimento das culturas deve ser simulado em condições de restrição hídrica, o que foi adotado neste estudo.

Para a cultura do trigo (Figura 4 A), em 63\% (7/11) das safras dos anos de LN, ocorreram rendimentos superiores à média de anos N; em 54\% (7/13) das safras dos anos de $\mathrm{EN}$, os rendimentos foram superiores à média dos anos N; e em 50\% (5/10) das safras em anos N, os rendimentos foram superiores à média dos anos $\mathrm{N}$.

Para a cultura da soja (Figura 4 B), em 79\% (11/14), $73 \%(8 / 11)$ e $67 \%$ (6/9) das safras em anos de EN, LN e $\mathrm{N}$, respectivamente, ocorreram rendimentos superiores à média dos anos $\mathrm{N}$.

Para a cultura do milho (Figura 4 C), em 82\% (9/11) das safras de LN, em 79\% (11/14) das safras dos anos de EN e, em 67\% (6/9) das safras em anos N, o rendimento foi superior a média dos anos neutros.

A análise dos resultados deste estudo evidencia que o baixo conteúdo de água no solo, em Santa Maria, não é um fator limitante para a cultura do trigo, mas o é para culturas de verão (soja e milho), especialmente durante anos classificados como neutros em relação ao fenômeno ENOS (Figura 3). Em conseqüência, é nos anos neutros que se têm maiores riscos de perdas de rendimento de grãos, das culturas de verão em Santa Maria. Esses resultados concordam com Berlato \& Fontana (2003), que também encontraram maiores deficiências hídricas no solo, em algumas regiões da metade Norte do Rio Grande do Sul (Baixo Vale do Uruguai e Missões), em anos neutros; os resultados concordam, também, com Berlato et al. (2005), que encontraram, em anos neutros, os maiores desvios negativos de rendimento de grãos de milho, considerando-se a média de todo o Estado.
Os anos neutros têm se mostrado mais irregulares, em termos de distribuição de precipitação no Rio Grande do Sul, durante o ciclo de desenvolvimento das culturas de
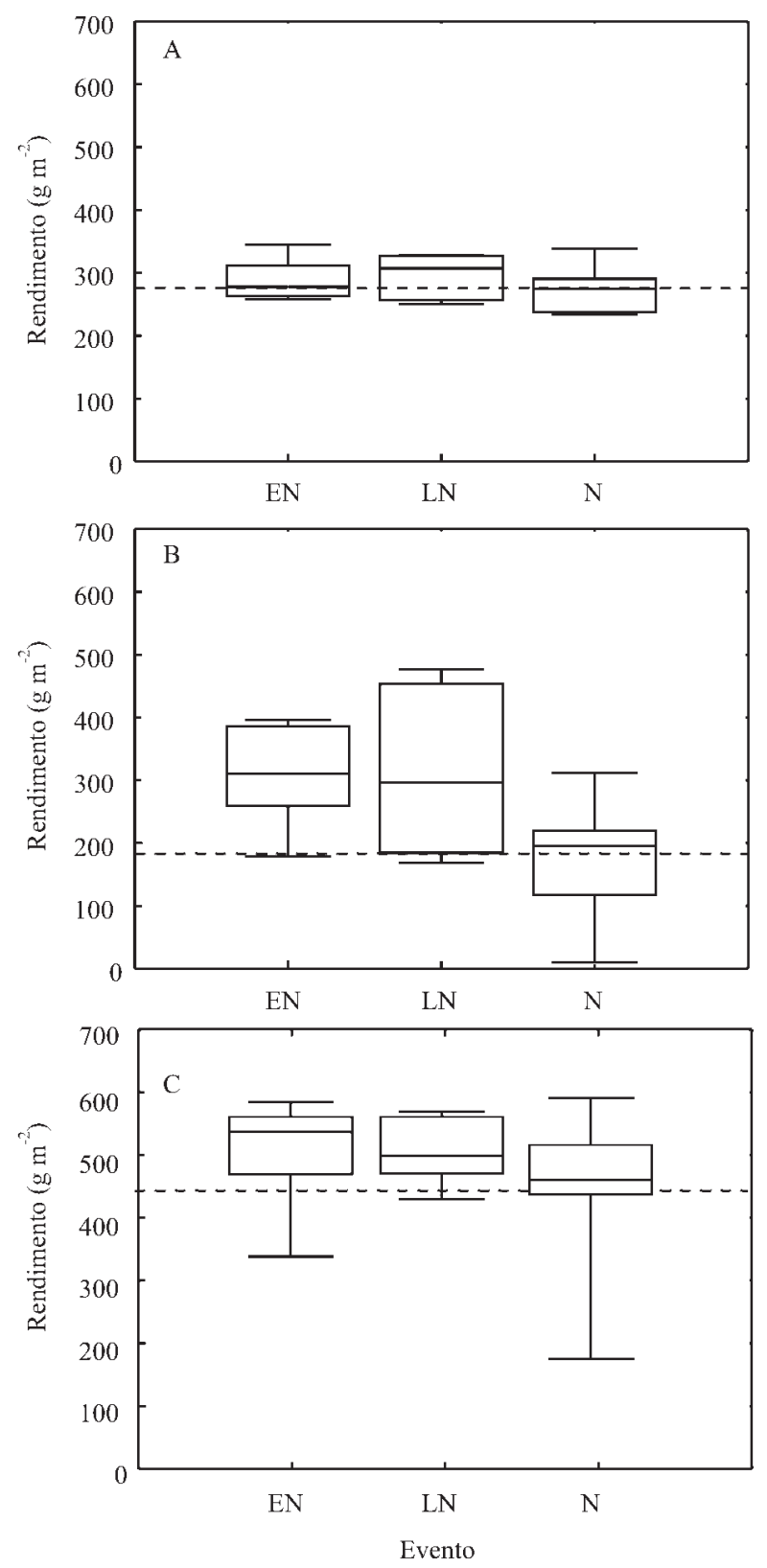

Figura 4. Distribuição do rendimento de grãos de trigo (A), soja (B) e milho (C), simulado com os modelos de Amir \& Sinclair (1991b), Sinclair (1986) e Muchow \& Sinclair (1991), respectivamente, no período de 1969-2003, associado aos eventos de El Niño(EN), La Niña (LN) e Neutros (N), para Santa Maria, RS. A linha cheia horizontal, no interior da caixa, representa o percentil de 50 (mediana); a linha tracejada representa a média dos anos neutros; o final das caixas representa os percentis de 25 e 75; as barras representam os percentis de 10 e 90. 
verão. Dois exemplos recentes, e que são dados independentes para comprovar as tendências deste estudo, foram o verão de 2003/2004 e o de 2004/2005, ambos classificados como neutros em relação ao fenômeno ENOS. Durante o verão 2003/2004, em Santa Maria, houve precipitação de $357,3 \mathrm{~mm}$, em dezembro de 2003, com ocorrência de enchentes, enquanto que a precipitação de janeiro de 2004 foi de apenas $21,7 \mathrm{~mm}$, e causou prejuízos nas lavouras de milho e soja no Estado. O verão 2004/ 2005 foi ainda mais seco no Estado, com precipitação de $62,2 \mathrm{~mm}$, em dezembro de 2004, e 49,8 mm, 59,4 mm e $55,4 \mathrm{~mm}$ em janeiro, fevereiro e março de 2004, respectivamente, o que causou uma das maiores reduções na produção de milho e soja da história do Estado, que colheu 50\% a menos em relação ao ano anterior (2003/ 2004); além disso, o produto colhido teve baixa qualidade de grãos para comércio (Conab, 2005).

A tendência do rendimento potencial simulado para as três culturas foi oposta ao rendimento com limitação hídrica (Figura 2), pois em anos com elevado deficit hídrico, o rendimento potencial tendeu a ser mais elevado, enquanto os valores de rendimento com limitação hídrica atingiram o seu menor valor. Um exemplo deste fato é o ano de 1990/1991, simulado para a cultura do milho, quando ocorreu o maior rendimento potencial $\left(661 \mathrm{~g} \mathrm{~m}^{-2}\right)$, e o rendimento com limitação hídrica foi o terceiro menor valor durante o período estudado (309 $\mathrm{g} \mathrm{m}^{-2}$ ). Estes resultados permitem inferir que o uso de irrigação, em anos com deficiência hídrica, podem aumentar o rendimento de grãos das culturas de verão (Bergamaschi et al., 2004), pois anos secos possuem maior número de dias límpidos, o que aumenta a disponibilidade de radiação solar para o dossel vegetal.

A maior freqüência de rendimento de grãos de milho, em anos de LN, acima da média dos anos N (82\%, Figura 4 C), em relação às outras duas espécies, pode ter ocorrido em razão da elevada profundidade do sistema radicular, utilizada no modelo de simulação desta cultura (1,2 m), o que aumenta a extração de água pelo sistema radicular. Como em anos de $\mathrm{LN}$ tem-se maior disponibilidade de radiação solar (Berlato \& Fontana, 2003; Berlato et al., 2005), isto pode ter como conseqüência um rendimento mais elevado da cultura do milho nesses anos. Além disso, o milho é uma planta de metabolismo $\mathrm{C}_{4}$, enquanto a soja e o trigo são plantas $\mathrm{C}_{3}$. Plantas $\mathrm{C}_{4}$ são mais eficientes na produção de biomassa, especialmente quando a temperatura do ar é elevada.

Outro fator que pode explicar o maior número de anos La Niña com rendimento acima da média dos neutros é a variabilidade na distribuição de chuvas durante o verão no
Estado do Rio Grande do Sul. Esta variabilidade pode ir da chuva significativa, durante a fase mais crítica do milho, ao deficit hídrico que se estende da pré-floração até o início do enchimento de grãos, como relatado em Bergamaschi et al. (2004), para a ano de La Niña 1998/1999.

Estes resultados concordam com Berlato et al. (2005), que ralatam uma maior frequência de desvios positivos (3/9) de rendimento de grãos de milho em anos de La Niña, comparada à freqüência de desvios negativos (1/11) de rendimento em anos de El Niño.

Para a cultura do trigo, observou-se que em anos de EN ocorreram desvios negativos de 62\% (8/13), em relação à média de todo o período estudado; isto se deve ao excesso de chuva na primavera (Fontana \& Berlato, 1997), o que aumenta as condições favoráveis às doenças, leva à maior frequiência de saturação do solo e à redução na radiação solar, fatores estes que reduzem o crescimento aéreo e radicular, afetando negativamente os componentes do rendimento (Cunha et al., 1999).

A menor freqüência de desvios negativos, 36\% (4/11), que ocorreram em anos de LN, aproximam-se daqueles relatados em Cunha et al. (1999), 57\% (13/23) e 33\% (5/15), para anos de EN e LN, respectivamente. Porém, para anos N, os desvios negativos de 60\% (6/10) e positivos de 40\% (4/10), em relação à média de todo o período, foram opostos àqueles observados por Cunha et al. (1999) de 37\% (15/40) para desvios negativos e 63\% (25/40) para desvios positivos. Não foi possível levantar hipóteses, para explicar estas diferenças para anos neutros entre os resultados deste trabalho e os relatados por Cunha et al. (1999).

Os menores valores de rendimento simulado de soja (11,0 $\mathrm{g} \mathrm{m}^{-2}$ ) e milho (178,9 $\left.\mathrm{g} \mathrm{m}^{-2}\right)$ foram verificados na safra 1985/1986. Estes resultados concordam com aqueles apresentados por Berlato \& Fontana (2003), já que estes anos caracterizaram-se como de forte estiagem no período que se estendeu do final da primavera até o final do verão.

\section{Conclusões}

1. Menor disponibilidade hídrica no solo, em Santa Maria, RS, está associada a anos neutros, enquanto a maior disponibilidade hídrica no solo está associada a eventos de El Niño.

2. Anos de La Niña são os mais favoráveis ao rendimento de grãos da cultura do trigo, e o baixo conteúdo de água no solo não é um fator limitante para esta cultura em Santa Maria, RS. 
3. Anos de El Niño são os mais favoráveis ao rendimento de grãos das culturas da soja e milho; e os anos classificados como neutros, em relação ao ENOS, são os de maior risco de perda de rendimento de grãos dessas duas culturas, em razão da menor disponibilidade hídrica no solo.

\section{Agradecimentos}

Ao CNPq, pelas bolsas concedidas a Arno Bernardo Heldwein e Galileo Adeli Buriol.

\section{Referências}

AMIR, J.; SINCLAIR, T.R. A model of the temperature and solar radiation effects on spring wheat growth and yield. Field Crops Research, v.28, p.47-58, 1991a.

AMIR, J.; SINCLAIR, T.R. A model of water limitation on spring wheat growth and yield. Field Crops Research, v.29, p.59-96, 1991 b.

ANDRESEN, J.A.; ALAGARSWAMY, G.; ROTZ, A.; RITCHIE, J.T.; LeBARON, A.W. Weather impacts on maize, soybean, and alfalfa production in the Great Lakes Region, 1895-1996. Agronomy Journal, v.93, p.1059-1070, 2001.

BERGAMASCHI, H.; DALMAGO, G.A.; BERGONCI, J.I.; BIANCHI, C.A.M.; MÜLLER, A.G.; COMIRAN, F.; HECKLER, B.M.M. Distribuição hídrica no período crítico do milho e produção de grãos. Pesquisa Agropecuária Brasileira, v.39, p.831-839, 2004.

BERLATO, M.A.; FARENZENA, H.; FONTANA, D.C. Associação entre El Niño Oscilação Sul e a produtividade do milho no Estado do Rio Grande do Sul. Pesquisa Agropecuária Brasileira, v.40, p.423-432, 2005.

BERLATO, M.A.; FONTANA, D.C. El Niño e La Niña: impactos no clima, na vegetação e na agricultura do Rio Grande do Sul; aplicações de previsões climáticas na agricultura. Porto Alegre: Ed. da UFRGS, 2003. 110p.

BERLATO, M.A.; FONTANA, D.C. Variabilidade interanual da precipitação pluvial e rendimento da soja no Estado do Rio Grande do Sul. Revista Brasileira de Agrometeorologia, v.7, p.119-125, 1999.

CAMPBELL, G.S.; DIAZ, R. Simplified soil-water balance models to predict crop transpiration. In: BIDINGER, F.R.; JOHANSEN, C. Drought research priorities for the dryland tropics. Parancheru, India: Icrisat, 1988. p.15-26.

CANE, M.A. Understanding and predicting the world's climate system. In: ROSENZWEIG, C.; BOOTE, K.J.; HOLLINGER, S.; IGLESIAS, A.; PHILLIPS, J. (Ed.). Impacts of EI Niño and climate variability on agriculture. Madison: American Society of Agronomy, 2001. p.1-20. (ASA. Special publication, 63).

CONAB. Safras 1990/91 a 2004/2005: séries históricas. Disponível em: <http://www.conab.gov.br>. Acesso em: 13 set. 2005.
CPTEC. El Niño e La Niña: eventos anteriores. Disponível em: <http://www.cptec.inpe.br/enos>. Acesso em: 25 maio 2004.

CUNHA, G.R.; DALMAGO, G.A.; ESTEFANEL, V. ENSO influences on wheat crop in Brazil. Revista Brasileira de Agrometeorologia, v.7, p.127-138, 1999.

EMBRAPA. Centro Nacional de Pesquisa de Solos (Rio de Janeiro, RJ). Sistema brasileiro de classificação de solos. Brasília: Embrapa-SPI; Embrapa-CNPS, 1999. 412p.

EMBRAPA. Centro Nacional de Pesquisa de Trigo (Passo Fundo, RS). Indicações técnicas da Comissão Sul-Brasileira de Pesquisa de Trigo - 2004. Disponível em: <http://www.cnpt.embrapa.br/ rcsbpt04/index.htm>. Acesso em: 20 abr. 2004a.

EMBRAPA. Centro Nacional de Pesquisa de Trigo (Passo Fundo, $\mathrm{RS}$ ). Indicações técnicas para a cultura de soja no Rio Grande do Sul e em Santa Catarina 2004/2005. Disponível em: <http:// www.cnpt.embrapa.br/i_soja.htm>. Acesso em: 20 abr. 2004b.

FONTANA, D.C.; BERLATO, M.A. Influência do El Niño Oscilação Sul sobre a precipitação do Estado do Rio Grande do Sul. Revista Brasileira de Agrometeorologia, v.5, p.127-132, 1997.

GHIDEY, F.; GREGORY, J.M.; McCARTY, T.R.; ALBERTS, E.E. Residue decay evaluation and prediction. Transactions of the American Society of Agricultural Engineers, v.28, p.102-105, 1985.

GILL, B.S.; JALOTA, S.K. Evaporation from soil in relation to residue rate, mixing depth, soil texture and evaporativity. Soil Technology, v.8, p.293-301, 1996.

GLANTZ, M.H. Currents of change: impacts of El Niño and La Niña on climate and society. $2^{\text {nd }}$ ed. Cambridge: Cambridge University Press, 2001. 252p.

MALUF, J.R.T.; MATZENAUER, R.; CAIAFFO, M. Zoneamento agroclimático da cultura do milho por épocas de semeadura, no Estado do Rio Grande do Sul. Pesquisa Agropecuária Gaúcha, v.6, p.3952, 2000.

MOREIRA, A.M.; ANGULO FILHO, R.; RUDORFF, B.F.T. Eficiência do uso de radiação e índice de colheita em trigo submetido a estresse hídrico em diferentes estádios de desenvolvimento. Scientia Agricola, v.56, p.597-603, 1999.

MUCHOW, R.C.; SINCLAIR, T.R. Water deficit effects on maize yields modeled under current and “Greenhouse” climates. Agronomy Journal, v.83, p.1052-1059, 1991.

MUCHOW, R.C.; SINCLAIR, T.R.; BENNET, J.M. Temperature and solar radiation effects on potential maize yield across locations. Agronomy Journal, v.82, p.338-343, 1990.

SINCLAIR, T.R. Water and nitrogen limitations in soybean grain production. I. Model development. Field Crops Research, v.15, p.125-141, 1986.

SINCLAIR, T.R.; KITANI, S.; HINSON, K.; BRUNIARD, J.; HORIE, T. Soybean flowering date: linear and logistic models based on temperature and photoperiod. Crop Science, v.31, p.786-790, 1991.

$\overline{\text { Recebido em } 3 \text { de maio de } 2005 \text { e aprovado em } 15 \text { de março de } 2006}$ 
